\title{
Contrasting patterns of memory span decrement in ageing and aphasia
}

\author{
MARCEL KINSBOURNE \\ From the Division of Pediatric Neurology, Duke University Medical Center, \\ Durham, North Carolina, U.S.A.
}

SUMMARY As compared with young adult controls, elderly subjects matched for verbal ability showed only a minor deficit in mean auditory letter memory span but proportionately more dependence upon the occurrence of letter groupings prevalent in the written language. An aphasic $\vec{\circ}$ group that also had a relatively limited mean letter span conversely made no detectable use at all of such groupings. These findings suggest that the aged tend if anything towards undue assimilation of $\bar{\omega}$ information into preformed schemata, while aphasics accommodate to individual messages without evidence of such organization.

Behavioural deficits are defined in terms of impaired test performance. But impaired test performance may be a final common pathway for expression of quite diverse types of impairment. The defective process that underlies a performance decrement could have been impaired in more than one way, depending on whether the decrement was the result, for instance, of the ageing process, or attributable to aphasia. One such dichotomy might relate to the balance between assimilation and accommodation in cognitive function (Piaget, 1950). In the course of cognitive development, information about invariant features of the environment is retained in memory and the resulting 'schemata' are then matched against subsequent events so that they may be categorized. Assimilation is the process by which input is matched to samples from previously stored information. The event represented by the sample which yields the closest fits is then taken to have recurred. If assimilation alone occurred, then any information that did not represent the recurrence of a previously experienced event would be discarded, and assume no control over behaviour. In fact, assimilation is tempered by accommodation, by means of which deviations from previous experience are noted. In this way schemata are constantly amplified, refined, and increased in number.

The balance between assimilation and accommodation could be upset in either direction, with different consequences. Excessive assimilation distorts the perception of events into non- $\stackrel{N}{\overrightarrow{0}}$ veridical conformity with expectation based on $\stackrel{0}{N}$ cumulative experience. In contrast, undue 은 accommodation deprives the observer of the usefulness of schema for enhancing informatiog pick-up. In either case, performance suffers fro the resulting maladaptive behaviour. We no determine experimentally whether either or botf such impairments may characterize defective performance by differently handicapped subject groups on immediate recall as measured by a test of letter memory span. Elderly subjects (Gilbert, 1941; Talland, 1965) and patients with brain damage resulting in aphasia are both limited in respect of letter span. Elderly persons have had much opportunity to internalize schemata and are perhaps rigid in applying them (Botwinick, 1967). Do they give evidence of excessive assimilation? If aphasics have lost access to schemata that organize verbal experiences, might they be found to accommodate to an inexpedient degree?

When multiple items are to be remembered, it is useful to group them according to some over- $\rightarrow$ learned linguistic rule. It is the number of such supraordinate groups or chunks (Miller, 1956), N rather than the greater number of the con- $N$ stituent items, that represents the load on the memory store, and this load is thus lightened by chunking. For instance, the letter span of apprehension is a function of the codability of the sequence, whether experimentally manipu- $\stackrel{\mathscr{D}}{?}$ lated (Warrington, Kinsbourne, and James, 
1966), systematically varied in its resemblance to the written language (Miller, Bruner, and Postman, 1954), or held constant but presented to subjects with different overlearned coding strategies (Kinsbourne and Cohen, 1971). To demonstrate the effect, Miller et al. (1954) generated eight-letter sequences at four levels of approximation to the language. Zero order is drawn at random from the alphabet, first order is weighted for relative letter frequency, and second and fourth order preserved the relative prevalence of bigrams and tetragrams respectively in the written language. These four orders of approximation also lead to increasingly better retention when the material is successively presented in either the visual (Baddeley, 1964) or the acoustic (Kinsbourne, 1970a) mode. Similar results were obtained by Gibson, Pick, Osser, and Hammond (1962) with letter sequences so constructed that some of them incorporated 'spelling patterns', while others did not.

Varying the order of approximation of auditorily presented letter sequences has an effect on memory span of old as well as young subjects (Kinsbourne, 1970a, 1971). Thus both these groups are able to 'assimilate' material into schemata constructed through experience of the written language and thereby retain more information. On the other hand, there is a limit to the extent to which assimilation is useful for these materials, as even the closest approximations to the language still fall short of the use of actual words, which are the schemata constructed from previous experience. Now, if old persons tend toward excessive assimilation, then their dependence on approximation to the language should be greater than that of the young. Their tendency to assimilate input into an expected framework would be less harmful for the approximations closer to the language; however, some errors would obtrude when the approximations fall short of being completethat is, of comprising actual words. Conversely, if aphasics can no longer encode on the basis of the contingencies of the English language, assimilation is precluded and the effect of approximation to English should be lost. The subject accommodates as best he can to the individual items without attempting to help himself by the formation of supraordinate groups.

\section{SUBJECTS}

1. Thirteen healthy elderly persons, volunteers, with adequate hearing verified audiometrically, mean age $79 \cdot 6$, range $65-87$ years.

2. Thirteen healthy normal hearing young adults, volunteers, mean age $32 \cdot 5$, range $19-35$ years. The young subjects were matched with the elderly on their Mill Hill Vocabulary raw score.

3. Thirteen aphasic patients, mean age 49.5 , range 24-61 years, seen consecutively after cerebrovascular accidents, were able to take the test. The aphasia in each case was documented on the Minnesota Test for Differential Diagnosis of Aphasia. All had receptive as well as expressive language disorder. Only subjects who could repeat correctly at least six sequences were included in the study.

\section{METHODS}

Fifteen sequences of letters were constructed at each of four orders of approximation (zero, first, second, and fourth). There were three sequences for each approximation of length four, five, six, seven, and eight letters, respectively. These were spoken in a female voice at a rate of one item per second and recorded on magnetic tape. The sequences were derived from Miller et al. (1954).

The sequences were presented in blocks, starting with the shortest and continuing with sequences of increasing length within each block. The orders of approximation were randomized. At each trial, subjects were asked to wait till the sequence was played through, then to repeat as much of it as they could remember, in the correct order.

Subjects in groups 1 and 2 were given the Raven's Coloured Progressive Matrices Test and the Mill Hill Vocabulary Test.

\section{RESULTS}

Responses were scored so that credit was given only for sequences correctly reproduced both as regards the constituent letters and their sequence. Mean number of correctly repeated sequences for the subject groups at each order of approximation are shown in Table 1.

\section{ANALYSIS OF VARIANCE This was done using a}

TABLE 1

MEAN NUMBER OF CORRECTLY REPEATED SEQUENCES (MAXIMUM 15)

\begin{tabular}{|c|c|c|c|c|}
\hline \multirow[t]{2}{*}{ Group } & \multicolumn{4}{|c|}{ Approximation } \\
\hline & 0 & 1 & 2 & 4 \\
\hline $\begin{array}{l}\text { 1. Young } \\
\text { 2. Elderly } \\
\text { 3. Aphasic }\end{array}$ & $\begin{array}{l}7 \cdot 4 \\
5 \cdot 8 \\
4 \cdot 7\end{array}$ & $\begin{array}{r}10 \cdot 3 \\
7 \cdot 5 \\
4 \cdot 8\end{array}$ & $\begin{array}{r}11 \cdot 2 \\
9 \cdot 2 \\
5 \cdot 5\end{array}$ & $\begin{array}{r}10 \cdot 8 \\
9 \cdot 3 \\
5 \cdot 7\end{array}$ \\
\hline
\end{tabular}


programme which is part of the IBM 360 Scientific Subroutines Package. The results are shown in Table 2.

TREND ANALYSES These were done using MANOVA (Cole and Grizzle, 1966), with the results shown in Table 3.

TABLE 2

RESULTS OF ANALYSIS OF VARIANCE

\begin{tabular}{lrrrrrr}
\hline & $\begin{array}{c}\text { Sum } \\
\text { square }\end{array}$ & DF & $\begin{array}{c}\text { Mean } \\
\text { square }\end{array}$ & $F$ & $P$ \\
\hline S & 318.42 & 12 & 26.54 & & \\
G & 609.71 & 2 & 304.85 & $13.10($ d.f. $=2,36)$ & $<0.01$ \\
$\mathbf{S} \times$ G & 558.46 & 24 & 23.27 & & \\
$\mathbf{A}$ & 191.71 & 3 & 63.90 & $35.90($ d.f. $=3,36)$ & $<0.01$ \\
$\mathbf{S} \times \mathbf{A}$ & 64.04 & 36 & 1.78 & & \\
$\mathbf{G} \times \mathbf{A}$ & 52.19 & 6 & 8.70 & $5.69($ d.f. $=6,72)$ & $<0.01$ \\
$\mathbf{S} \times \mathbf{G} \times \mathbf{A}$ & 110.31 & 72 & 1.53 & & \\
\hline
\end{tabular}

$\mathbf{S}=$ Subjects $; \mathbf{G}=$ Groups; $\mathbf{A}=$ Approximations .

TABLE 3

RESULT OF TREND ANALYSES

\begin{tabular}{llll}
\hline Group & \multicolumn{1}{c}{ Trend } & & \\
\hline 1. Young & Linear & $\mathrm{F}=4.75$ & $\mathrm{P}<0.05$ \\
& Quadratic & $\mathrm{F}=51.48$ & $\mathrm{P}<0.01$ \\
2. Elderly & Linear & $\mathrm{F}=25.11$ & $\mathrm{P}<0.01$ \\
& Quadratic & $\mathrm{F}=25.25$ & $\mathrm{P}<0.001$ \\
3. Aphasic & Linear & $\mathrm{F}=0.01$ & $\mathrm{P} \quad \mathrm{NS}$ \\
& Quadratic & $\mathrm{F}=4.44$ & $\mathrm{P}<0.05$ \\
& & & \\
\hline
\end{tabular}

Group 1 and Group 2 SD in linear trend $(F=4 \cdot 01)$.

Group 1 and Group 3 SD in linear $(F=13 \cdot 10)$ and quadratic trends $(\mathrm{F}=10 \cdot 67)$.

Group 2 and Group $3 \mathrm{SD}$ in quadratic trend $(F=12 \cdot 83)$.

There was a significant effect of approximation to the language on letter memory span for the young and the elderly subject groups, but none for the aphasics. The effect of increasing approximation was proportionally greater for the elderly than the young group. The elderly and young control groups did not differ on the Vocabulary Test (mean scores $17 \cdot 3$ and 16.5 respectively, $t=0 \cdot 5$, NS), but the young subjects were superior on the Progressive Matrices (with mean score of 32.7 as compared with 20.3 , $t=6 \cdot 2, \mathrm{P}<0.01)$.

\section{DISCUSSION}

Matching on a vocabulary test ensures comparability of young and older subject samples, and of groups matched in this way the younger would then be expected to show superiority in Matrices performance, a measure of general intelligence. Vocabulary testing of the aphasic group would have been fruitless for matching purposes, as this would have been vitiated by the selective language disorder.

With increasing approximation of letter sequence to spelling prevalent in the written language, there is a corresponding increase in the auditory immediate memory span of normal young subjects. The elderly group showed an increase in span with increasing codability which was proportionately in excess of the significant increment found with the young subjects. In striking contrast, the aphasics made no significant gains at all in relation to increased codability.

While both the young and the elderly group showed overall gains in letter span with increasing approximation to the language, the locus of major change differed. The elderly group continued to gain from zero to second order approximation, but the major increment for the young was between zero and first order. It would seem that the minimal cues available in first order were sufficient to permit young subjects to impose organization on the material while older subjects continued to benefit as the similarity to English spelling further increased. This difference is in the predicted direction.

The findings may be viewed in terms of imbalance between processes of accommodation and assimilation. The elderly group benefits, even disproportionately, from higher-order approximation of sequences to the language, which conform to and may thus be assimilated into preexisting cognitive schemata. The aphasic, on the contrary, accommodates to the individual items and fails to make use of the opportunity of assimilating the more codable sequences, presumably because the relevant schemata are no longer available to him.

If the effect of ageing on cognition has any characteristics that distinguish it from other forms of cumulative diffuse brain damage, there should be predictable differences between the mechanisms of age-related deficit and brain damage deficit such as aphasia. Whether the dichotomy here introduced in relation to letter memory span has generality for age effects on memory and learning remains to be seen. Whether the verbal memory deficit in aphasia (Zangwill, 1946) is characterized by a pre- 
dominance of accommodation over assimilation is also as yet unknown.

If the dominant left cerebral hemisphere contributes disproportionately to verbal recoding, then verbal material should demonstrably be better recoded when presented to the right visual half field than to the left. This is because contralateral input gains more direct access to the relevant hemisphere (Kimura, 1966) or because preparatory verbal set biases attention to right of centre (Kinsbourne, 1970b). Dornbush and Winnick (1965) found that normal righthanded subjects perceive letter sequences better in the right half field and that this superiority increases with increasing approximation of the sequences to English spelling.

I am grateful for the assistance of Mrs. Linda Lohrbauer with the testing of the aphasic patients. The work was supported by The Veterans Administration and Stroke Center Grant No. 06233.

\section{REFERENCES}

Baddeley, A. D. (1964). Immediate memory and the 'perception' of letter sequences. Quarterly Journal of Experimental Psychology, 16, 364-367.

Botwinick, J. (1967. Cognitive Processes in Maturity and Old Age. Springer: New York.

Cole, J. W. L., and Grizzle, J. E. (1966). Applications of multivariate analysis of variance to repeated measurements experiments. Biometrics, 22, 810-828.

Dornbush, R. L., and Winnick, W. A. (1965). Right-left differences in tachistoscopic identification of paralogs as a function of order of approximation to English letter sequences. Percept. Motor Skills, 20, 1222-1224.

Ettlinger, G., and Moffett, A. M. (1970). Learning in dysphasia. Neuropsychologia, 8, 465-474.

Gibson, E. J., Pick, A., Osser, H., and Hammond, M. (1962). The role of grapheme-phoneme correspondence in the perception of words. American Journal of Psychology, 75, 554-570.

Gilbert, J. G. (1941). Memory loss in senescence. Journal of Abnormal and Social Psychology, 36, 73-86.

Kimura, D. (1966). Dual functional asymmetry of the brain in visual perception. Neuropsychologia, 4, 275-285.

Kinsbourne, M. (1970a). Optimal learning conditions for fast and slow learners. Proceedings of American Association on Mental Deficiency, Washington.

Kinsbourne, M. (1970b). The cerebral basis of lateral asymmetries in attention. Acta Psychologica, 33, 193-201.

Kinsbourne, M. (1971). Age effects on auditory letter memory span related to rate and sequential dependencies. (Submitted for publication.)

Kinsbourne, M. and Cohen, V. (1971). Memory span for English and for Hebrew consonants. (Submitted for publication.)

Miller, G. A. (1956). Human memory and the storage of information. IRE Transactions on Information Theory, IT-2, S 129-137.

Miller, G. A., Bruner, J. S., and Postman, L. (1954). Familiarity of letter sequences and tachistoscopic identification. Journal of Genetic Psychology, 50, 129-139.

Piaget, J. (1950). The Psychology of Intelligence. Harcourt: New York.

Talland, G. A. (1965). Three estimates of the word span and their stability over the adult years. Quarterly Journal of Experimental Psychology, 17, 301-307.

Warrington, E. K., Kinsbourne, M., and James, M. (1966). Uncertainty and transitional probability in the span of apprehension. British Journal of Psychology, 57, 3-16.

Zangwill, O. L. (1946). Some qualitative observations on verbal memory in cases of cerebral lesions. British Journal of Psychology, 37, 8-19. 